Mental Health Research Institute, University of Michigan, Ann Arbor, Michigan

\title{
Axon Swellings Produced in Vivo in Isolated Segments of Nerves*
}

\author{
By \\ REINHARD L. FRIEDE
}

With 5 Figures in the Text

(Received March 12, 1963)

\section{Introduction}

CAJAL ${ }^{5}$ showed that characteristic axon swellings develop not only in the proximal but also in the distal stumps of transected fibers; this observation has been confirmed by a number of investigators, ${ }^{4,7}$. Histochemically, ZELENA and LuBLINSKA ${ }^{11}$ have shown that there is an increase of cholinesterase activity in axon swellings of distal stumps. The transient focal accumulations of mitochondria in the axoplasm during the early phases of Wallerian degeneration ${ }^{8}$ probably represent a related, if not the same, phenomenon. Swollen axons in the peripheral stumps of severed nerves or tracts were frequently ignored in theoretical or experimental considerations on axonal flow, sometimes to the extent that the direction of an axon swelling was considered indicative of the location of its nerve cell.

The purpose of the present study was to try to elucidate some of the conditions which lead to the formation of axon swelling in fibers which were completely disconnected from the nerve cell. The mechanism responsible for what appears to be a local redistribution of axoplasm may differ fundamentally from that of the proximo-distal convection of axoplasm in non-damaged fibers. To eliminate the problem of distinguishing between local redistribution of axoplasm and normal "axonal flow", most of the present experiments were done on isolated segments of rat and cat sciatic nerve.

A preceding investigation had shown that typical "reactive" axon swellings can be produced in vitro by applying a current to a damaged nerve. With this in mind, some of the present experiments were designed to show that axonal swellings in isolated nerve segments develop at the site of potential differences, such as the injury currents, in a damaged nerve. However, evidence along this line is still only circumstantial.

\section{Material and Methods}

The conclusions reported in this paper were based on the results of 108 experiments in which sciatic nerves were used for four basic experiments, referred to in the text as experiments A, B, C, and D. Experiments A, B, and C were each done 20 times on rat nerves, experiment D was done 48 times using 16 cat and 32 rat nerves. Preceding these, 50 preliminary experiments were done to standardize the procedures used.

While cat sciatic nerves were studied in the first preliminary experiments, rat nerves proved to be of advantage because the histochemical distinction between axons and Schwann cells

* This investigation was supported by U.S. Public Health Service, Grant No. B-3250. 
was easier in them. There seemed to be relatively more enzyme in the Schwann cells of cat nerve than in rat.

In animals under ether anesthesia, the nerves were surgically exposed, then transected with scissors. For experiments A and B, the wound was closed immediately after the nerves were cut into $9-12 \mathrm{~mm}$ or $2-3 \mathrm{~mm}$ segments, respectively. In experiment $\mathrm{C}$, the nerve was bathed in situ in $3 \mathrm{MC} \mathrm{KCl}$ for $15 \mathrm{~min}$ before a $9-12 \mathrm{~mm}$ segment was cut; in addition, $\mathrm{KCl}$ was applied immediately after and $2^{1 / 2} \mathrm{hrs}$ after cutting. In experiment $\mathrm{D}$, a small cotton applicator was used to apply the $\mathrm{KCl}$ as selectively as possible on the cut ends of $9-12 \mathrm{~mm}$ segments.

All experiments were terminated after 5 hrs. The nerve samples were removed and fixed in $10 \%$ chilled formalin for $18 \mathrm{hrs} ; 30 \mu$ frozen sections were incubated for DPN-diaphorase ${ }^{3}$ and used for routine evaluation. Some sections of fixed material were incubated for lactie dehydrogenase. Other nerves were used for $30 \mu$ unfixed tissue frozen sections and incubated for succinic dehydrogenase and malic dehydrogenase. Some material was embedded in paraffin, and $10 \mu$ sections were stained with Bodian's silver method, the periodic acid-Schiff reaction, the alloxanSchiff reaction, and chromalum gallocyanin.

\section{Results}

The results of the experiments in the present study indicate that: a) the development of axon swellings can occur independently of the convection of axoplasm from a cell body, b) axon swelling occurs independently of the normal direction of axonal flow, in both ends of isolated segments of nerves and c) that such swellings develop at the site of known potential differences in the tissue. The following descriptions are of the DPN-diaphorase reaction. The comparative histochemistry of the axon changes is summarized at the end of the text.

\section{Comparison of Axonal Changes in Proximal and Distal Nerve Stumps}

Following a single transection of a nerve, swollen axons with marked increase of enzyme activity could be observed in both stumps. The proximal stumps always showed more extreme swelling and deformation of the axons with more increase of the enzyme reaction than the distal stumps. Swellings in proximal stumps, at their maximal development, usually were dropshaped, varicose, or beaded. In the distal stumps, the enzyme increase was more conspicuous than the swellings which were usually slender like a baseball bat or only slightly club-shaped, even during the phase of their maximal development. Histochemically, the differences between proximal and distal stumps were quantitative rather than qualitative.

The development of swellings in distal stumps started as early as $3 \mathrm{hrs}$ after cutting and subsided gradually within $1-2$ days. Axon swellings in the proximal stumps also started within 3 hrs and continued to increase up to 5 days after the nerve had been severed ${ }^{2}$. The difference of intensity of axonal changes in proximal and distal stumps was discernible as soon as axonal changes were evident, but it increased progressively with time.

\section{Axonal Changes in Both Stumps of a Nerve Segment (Experiment A)}

For this experiment, the segments were $9-12 \mathrm{~mm}$ long. Immediately after the nerve was cut, the wound was sutured; the segment was removed 5 hrs later. Axon swellings which contained a marked increase of enzyme activity developed at both ends. These changes were maximal at the cut ends and graded off toward the center of the segment. There was no marked or consistent difference between the two stumps of the nerve segment (Fig.1).

Apparently, the development of these changes started immediately after the nerve was cut; a marked increase of enzyme activity was seen as early as $3 \mathrm{hrs}$ after cutting. After $12 \mathrm{hrs}$ and within the first 1-2 days, the development of swelling subsided.

\section{Axon Changes at the Stumps are Proportional to the Length of the Segment (Experiment B)}

Preliminary experiments showed that there were fewer axonal changes at the stumps of segments which were less than $4-5 \mathrm{~mm}$ long. The extent of changes was proportional to the length of these short segments; that is, the shorter the segment, the fewer the changes. In 20 experiments, using $2-3 \mathbf{m m}$ long segments, there was much less, and often a complete lack, 


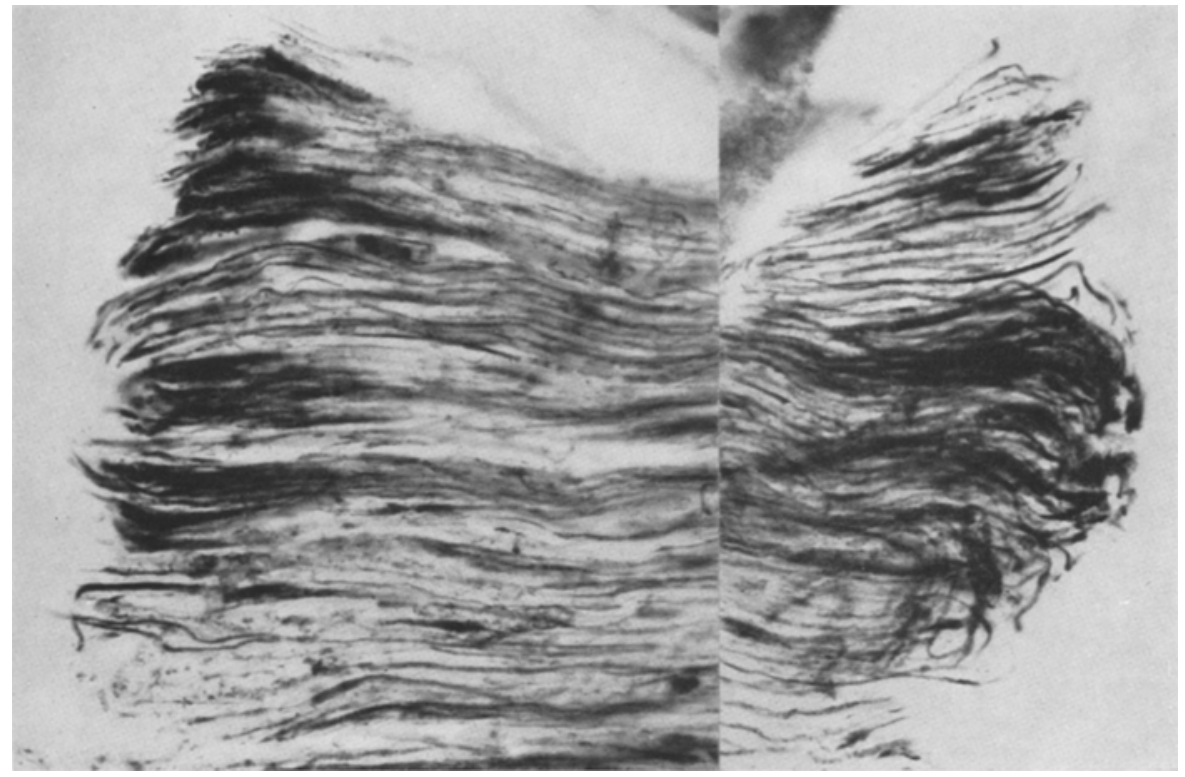

Fig. 1. Axon swellings and increased enzyme reaction in both stumps of a $9 \mathrm{~mm}$ segment of rat sciatic nerve. Both pictures were taken from the same section. DPN-diaphorase, $30 \mu$, ca $200 \times$

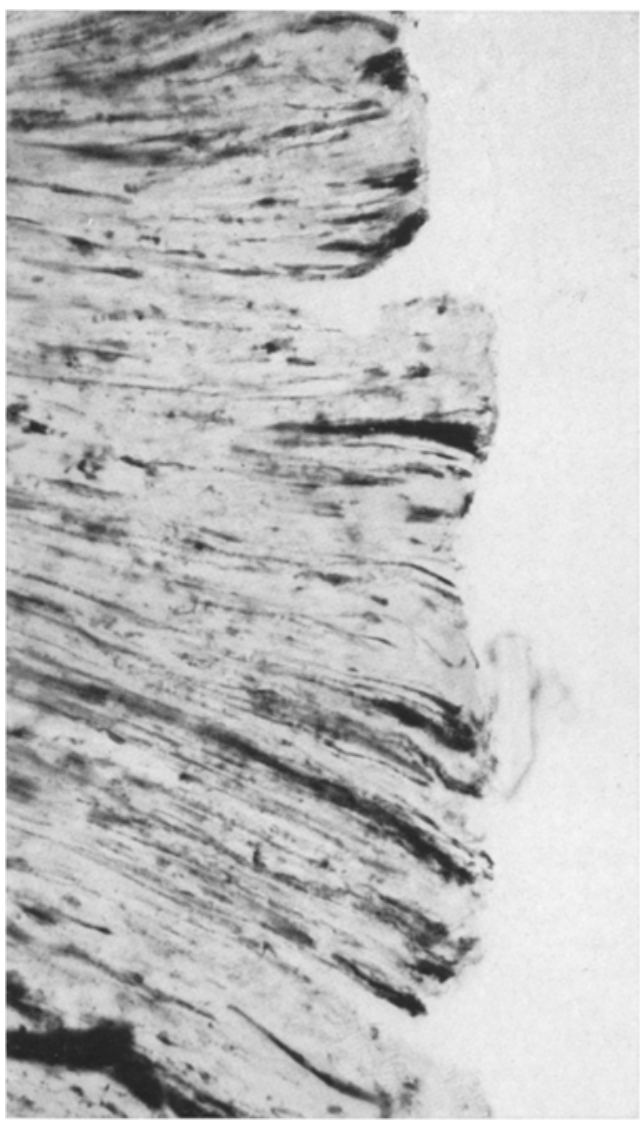

of development of swelling or enzyme accumulation in axons (Fig.2). Occasionally, there were a few scattered swollen fibers with increased enzyme activity. Stumps of $2-3 \mathrm{~mm}$ segments resembled those that had the $\mathrm{KCl}$ bath (Experiment C, see below) rather than those of experiment A where conditions were exactly the same except that the segments were longer. These observations were in agreement with the findings of ZeLENA and LUBLINSKA ${ }^{11}$ on cholinesterase in crushed nerve segments.

It is conceivable that there might be less axon swelling in short segments simply because less axoplasm is available; however, this would not explain why occasional axons did swell and contained marked increase of enzyme, even in $2 \mathrm{~mm}$ segments. Thus, we considered an alternative hypothesis: It is known that when a nerve is severed, an injury current develops between the intact portion and the depolarized stump. In a nerve segment, there should be injury currents at both ends, provided that there is sufficient polarized tissue left between the stumps.

Fig. 2. Stumps of a $2 \mathrm{~mm}$ segment of rat sciatic nerve. Only a few scattered swollen axons are visible. DPN-diaphorase, $30 \mu$, ca $300 \times$ 
Thus, if there was little or no polarized tissue between the stumps of short segments, this could explain the reduction of axonal changes. The following experiments were designed specifically to test the hypothesis that depolarization of the entire segment might have prevented the axon swelling.

\section{Effect of Depolarization on Axonal Changes in a Nerve Segment (Experiment C)}

If there is a relationship between the axon swellings and the injury eurrent, then depolarization of the entire segment should prevent the development of axon swellings. Thus, in experiment $\mathrm{C}$, the nerves were depolarized by bathing them in $3 \mathrm{M} \mathrm{KCl}$, in situ, for $15 \mathrm{~min}$ before

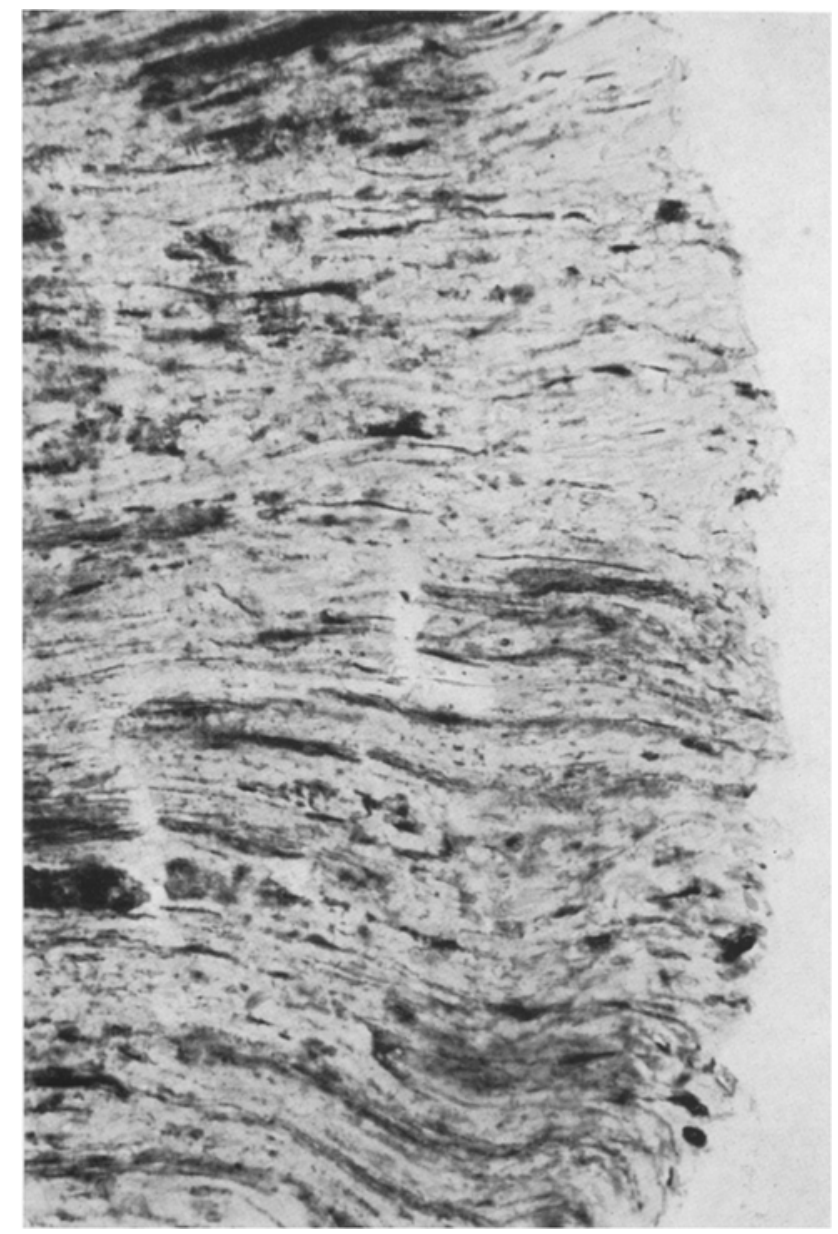

Fig. 3. No axonal changes at the stump of a $9 \mathrm{~mm}$ nerve segment; the entire segment was depolarized with $\mathrm{KC}$ before severing. DPN-diaphorase, $30 \mu$, ca $300 \times$

the 9-12 mm segments were cut. Axons in the stumps of these segments did not swell (Tig. 3) and the distribution of enzyme activity appeared to be normal throughout the segment. One exposure to $\mathrm{KCl}$ gave satisfactory results, but more complete effects were obtained by repeating the depolarization after $2^{1 / 2}$ hrs. The different results between experiment $A$ and experiment $C$ were so clear-cut that 10 coded samples from each experiment were all correctly identified (compare Figs. 1 and 3 ). 


\section{Effect of Topically Applied Depolarization (Experiment D)}

The purpose of experiment $D$ was to determine if the prevention of axonal changes after bathing the nerves in $3 \mathrm{M} \mathrm{KCl}$ (Experiment B) could have resulted from some specific effect of $\mathrm{KCl}$ on the axoplasm, rather than its depolarizing action on the central portion of the segment. If the depolarization hypothesis is correct, application of $\mathrm{KCl}$ selectively to the ends of the segments should enhance, or at least not antagonize, the development of axonal swellings. Thus, for this experiment, great care was taken to apply the $\mathrm{KCl}$ as selectively as possible to

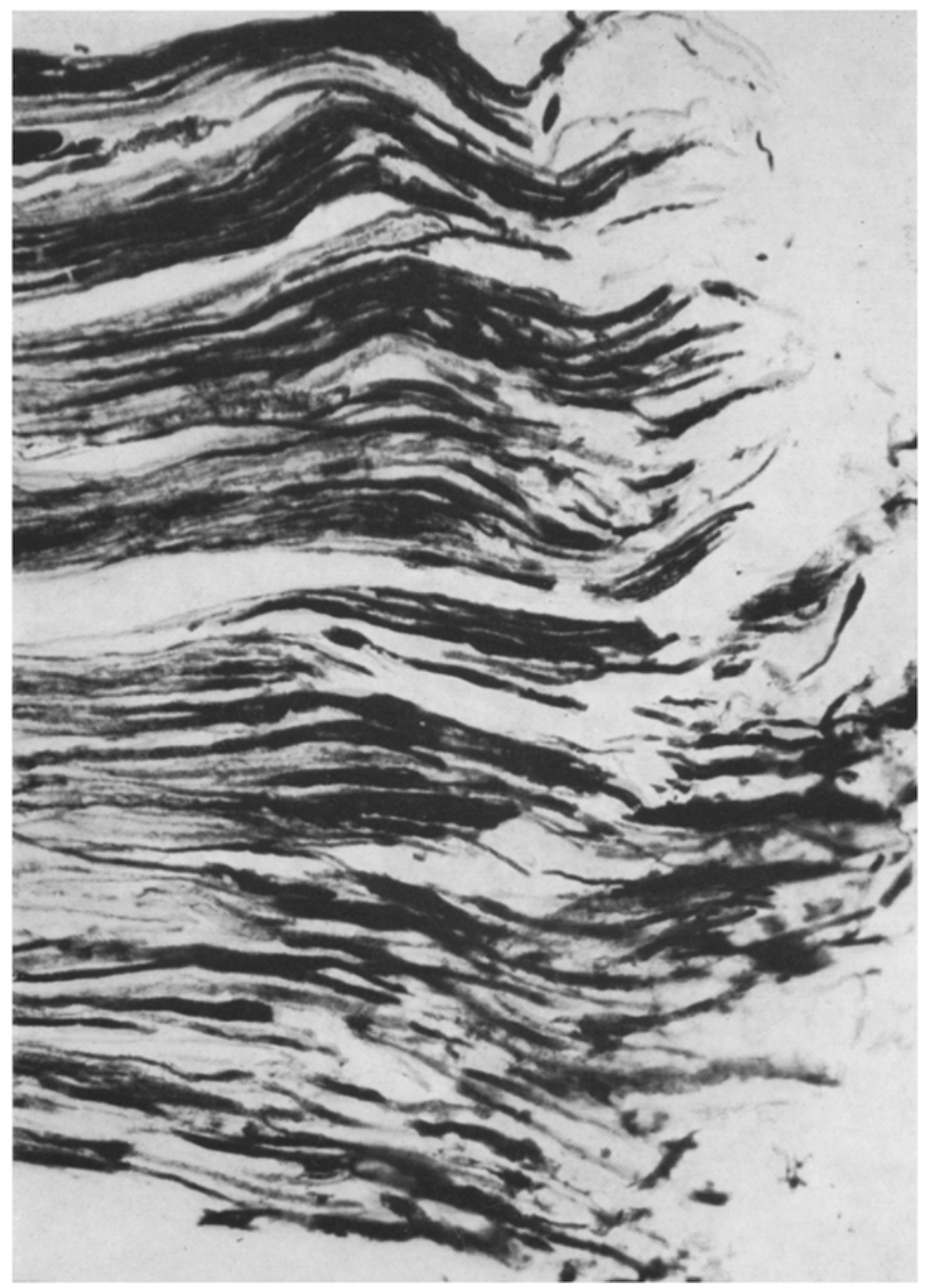

Fig. 4. Marked increase of axonal swelling following the application of KCl selectively to the stumps. DPN-diaphorase, $30 \mu, 350 \times$

the stumps. In 8 cat nerve segments, application of $\mathrm{KCl}$ to both stumps markedly increased the size of axon swellings and the accumulation of enzyme activity as compared with 8 untreated controls of equal length.

In 32 experiments with rat nerves, the findings were less consistent, probably because the thin rat nerve was penetrated much faster by the diffusion of $\mathrm{KCl}$. Increase over controls of axon swelling at the surface of the stump was only occasionally observed (Fig.4). Instead, numerous axon swellings were found scattered in a $1-2 \mathrm{~mm}$ long area adjacent to the stump (Fig.5). 
Comparative Histochemistry of Axonal Swellings in the Stumps of Nerve Segments

The distribution of lactic dehydrogenase and malic dehydrogenase, like that of DPNdiaphorase, was markedly increased in the swollen axons in the stumps; succinic dehydrogenase ${ }^{1}$ was only slightly increased. Also, the alloxan-Schiff reaction for proteins was slightly increased, but no change was discernible with the periodic acid-Schiff reaction and chromalum gallocyanin stain.

\section{Appendix}

Measurements of potential differences between the stump and the center of nerve segments were made on 26 cat sciatic nerves, using a Kintel-204A galvanometer. The nerve segments were dissected under ether anesthesia and used immediately; during measurement, they were kept in a moist chamber at $37^{\circ} \mathrm{C}$. Chlorinated silver electrodes were used. Potential differences

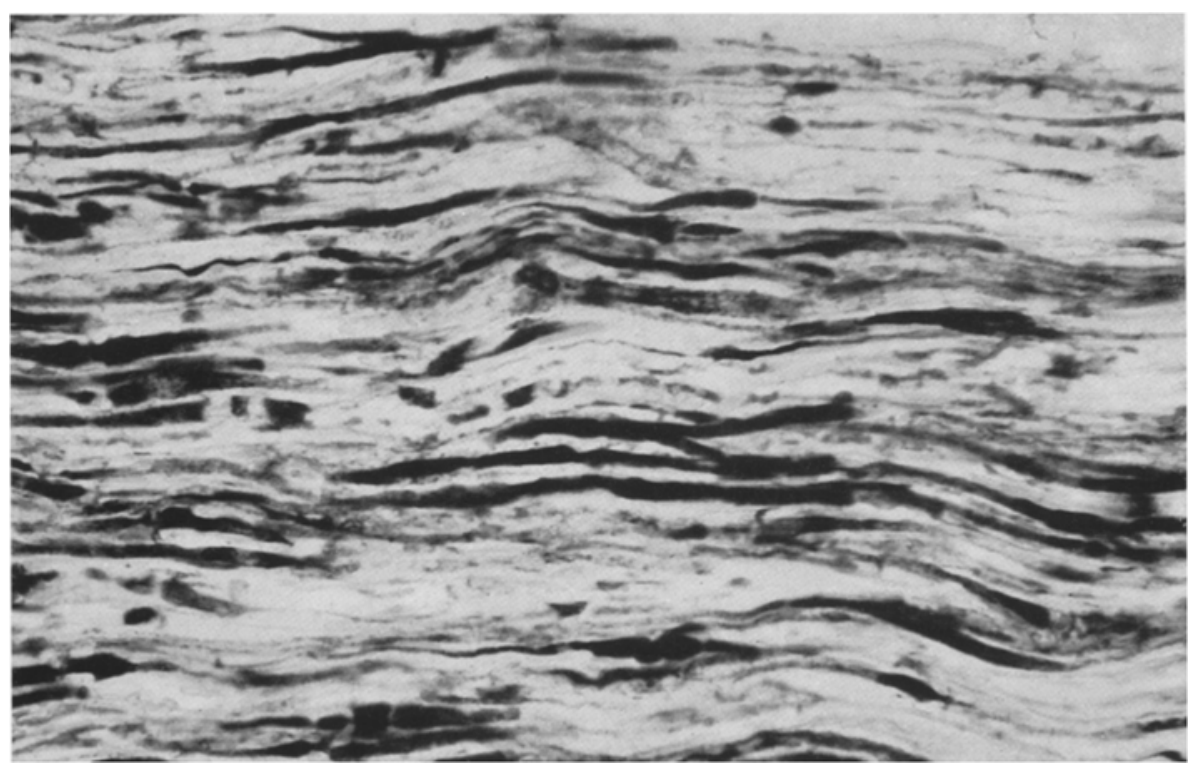

Fig.5. Markedly swollen axons scattered in a 1--2 mm long area adjacent to the stump. DPN-diaphorase, $30 \mu$, $350 \times$

in a range of 2-10 $\mathrm{mv}$ were recorded between the stump and the central part of the segment; exposure of the stumps to $3 \mathrm{M} \mathrm{KCl}$ produced a 5 -fold increase with a peak in a range of 20 to $40 \mathrm{mv}$, followed by a decline and often a reversal. Selectivity of application of $\mathrm{KCl}$ to the stumps was not imperative, apparently because the nerve sheath acted as a barrier delaying diffusion. The increase of the potential difference could not be elicited in nerves which had been bathed in situ in $3 \mathrm{M}$ KCl for $15 \mathrm{~min}$ before dissection (iike in experiment $\mathrm{C}$ ). While these studies were only explorative and incomplete, they helped to prove the development of the well-known injury currents in our type of preparation; also, they indicated that the interpretations of the effects of $\mathrm{KCl}$ were basically sound.

\section{Discussion}

The results of a preceding study showed that axoplasm, including a great number of axoplasmic enzymes and other constituents, could be electrophoretically moved along the axon in vitro. In damaged fibers, electrophoretic convection of

1 The much weaker reaction for succinic dehydrogenase may explain earlier reports of negative findings in distal stumps ${ }^{2}$. Other factors which may have entered were lack of data on very early changes and possible differences in surgical manipulation of the nerves and adjacent musscle tissue, 
axoplasm produced swollen deformed axons which were indistinguishable, both morphologically and histochemically, from pathological axon swellings in vivo.

Results of the present study of nerve segments in vivo show that axon swellings develop at the electronegative site of the demarcation (or injury) current. In isolated segments of nerves, axon swellings developed in both stumps independently of the normal direction of axonal flow. Procedures aimed at changing the potential differences in nerve segments also affected the development of axon swellings; no swellings developed if the entire segment had been depolarized with $\mathrm{KCl}$ and also in very short segments of nerve which probably had little or no polarized tissue left between the stumps. Application of $\mathrm{KCl}$ selectively to the stumps increased the development of axon swellings. Explorative studies (Appendix) evidenced the presence of injury currents in nerve segments; they were affected by $\mathrm{KCl}$ as postulated. It seemed difficult, thus, to conceive of any other explanation for the experimental results than their relationship to injury currents in the tissue. Yet, injury currents, even at their peak, were less than $1 / 1000$ of the currents which had been used to produce axonal swellings in vitro. Several factors could conceivably explain this difference: a) there was an indication that most of the in vitro current flowed in the perineural spaces (inactivation of Schwann cell enzyme activity) and very little in axons; the currents used in vitro were deliberately excessive as we tried to shorten exposure times in order to improve conditions for enzyme histochemistry. b) Resistance to axoplasmic flow would increase with speed and inversely with temperature. The latter was uncertain in the in vitro experiments in which the nerves had been cooled. c) The time of exposure and the extent of axonal swelling differed greatly in the two series of experiments.

A number of alternative hypotheses on the development of axon swellings could be ruled out by our observations: a) Non-specific concomitants of tissue trauma or cell injury would not explain the development of axon swellings since all segments were cut in the same manner, while marked and numerous axon swellings developed only in nerve segments which were $4-5 \mathrm{~mm}$ or longer. b) The explanation that osmotic forces caused the axon swelling was contradicted by the marked increase of the reactions for enzymes and protein in the swollen fibers. Assuming an osmotic swelling, one would have to postulate a decrease, rather than increase, of protein content or enzyme activity per volume. c) A local reactive synthesis of enzyme activity or of protein in the axon stumps, within $2-5 \mathrm{hrs}$, would have heen extremely unlikely and could not have explained the results in the short segments or of $\mathrm{KCl}$ bath experiments. It is of interest that ZELENA and LuBLINSKA ${ }^{11}$, in similar type experiments, measured cholinesterase and found that an increase of enzyme activity in the stumps was correlated with a decrease in the central portion, thus evidencing a local redistribution of axoplasm. d) A peristaltic activity of axons was recently claimed as a source of axoplasmic convection. It seems unlikely, although not impossible, that peristalsis could occur in opposite directions toward both stumps of a nerve segment. Also, BINGLEY and Thompson ${ }^{1}$ have shown that peristaltic phenomena may represent either the cause or the consequence of cytoplasmic motion; they demonstrated that cytoplasmic movements of amoebae are dependent on intracellular potential differences.

The axonal changes in distal stumps of transected fibers are less lasting and less extensive than those in the proximal stump. They represent a phenomenon 
well documented in the neuropathological literature ${ }^{5,7}$. They are also discernible in a recent radioautograph by $W_{\text {EISS }}{ }^{10}$, which shows the damming of $\mathrm{C}^{14}$ glucose in a constricted nerve. Previously, such observations had been attributed to recurrent fibers of regenerating nerves ${ }^{9}$. Such changes in distal stumps have been widely ignored in studies on axonal flow. Our results, in agreement with histochemical data on cholinesterase by ZELENA and LUBLINSKA ${ }^{11}$, indicate that axon swellings can result from confined shifts of axoplasm within short segments of fibers.

It is conceivable that the changes in the proximal stump of a severed nerve represent a complex interaction of both local phenomena and true damming of normal axoplasmic flow. Certainly, such local redistribution of axoplasm can develop independently of normal "axonal flow". Circumstantial evidence suggests strongly that injury currents between polarized and depolarized portions of nerves represent the forces responsible for axon swellings in injured nerves.

,The morphological and histochemical similarity between axonal changes in proximal and distal stumps may suggest that all movement of axoplasma, local redistribution, as well as "normal" axonal flow, may be controlled by physiological currents. Experimental studies are being continued in hopes of arriving at a more definite general concept of axoplasmic movements.

\section{Summary}

Within 3-5 hrs after cutting rat and cat sciatic nerves into segments which had no connection with the cell body, club-shaped axon swellings were observed at both ends of the segments. The swollen portion of these axons showed increased histochemical reactions for DPN-diaphorase, lactic dehydrogenase, malic dehydrogenase, succinic dehydrogenase, and protein; the increase lasted for $24-48 \mathrm{hrs}$ after the nerve was cut. The swollen axons were morphologically and histochemically similar to, but never as markedly changed, as those observed in the proximal stumps of severed nerves.

The development of axon swellings was prevented by depolarization of the entire segment with $\mathrm{KCl}$; however, if $\mathrm{KCl}$ was applied selectively to the stumps of the segment, it appeared to intensify rather than prevent the swelling. It was also noted that the extent of axon swelling was inversely proportional to the length of the segment. These observations suggested that the development and extent of axon swelling was related to the intensity of local injury currents in the tissue.

\section{Zusammenfassung}

Innerhalb von 3-5 Std nach Zerschneidung des Nervus ischiadicus von Ratten und Katzen in Segmente, die keine Verbindung mit dem Zellkörper besitzen, sind zylinderförmige Axonschwellungen an beiden Enden der Segmente zu beobachten. Der angeschwollene Teil dieser Axone zeigt verstärkte histochemische Reaktionen auf DPN-Diaphorase, Milchsäure-Dehydrogenase, Apfelsäure-Dehydrogenase, Bernsteinsäure-Dehydrogenase und Protein; dieser Anstieg hält 24-48 Std nach der Durchtrennung des Nervs an. Die Axonschwellungen sind sowohl morphologisch als auch histochemisch ähnlich - jedoch niemals in gleich starker Ausprägung - jenen, die in den proximalen Stümpfen von verletzten Nerven beobachtet werden. 
Die Entwicklung der Axonschwellungen kann durch Depolarisation des gesamten Segmentes mittels KCl verhindert werden; wenn jedoch $\mathrm{KCl}$ allein auf die Segmentstümpfe appliziert wird, scheint das die Schwellung eher zu intensivieren als zu verhindern. Es wurde ferner beobachtet, daß die Ausdehnung der Axonschwellungen verkehrt proportional zur Segmentlänge ist. Diese Beobachtungen erlauben die Annahme, daß die Entwicklung und die Ausdehnung von Axonschwellungen in Beziehung zur Intensität der lokalen Verletzungsströme im Gewebe steht.

\section{References}

${ }^{1}$ Binglfy, M. S., and C. M. Thompson: Bioelectric potentials in relation to movement in amoebae. J. theor. Biol. 2, 16-32 (1962).

2 FrIede, R. L.: Transport of oxidative enzymes in nerve fibers; a histochemical investigation of the regenerative cycle in neurons. Exp. Neurol. 1, 441-466 (1959).

3 - L. M. Fleming and M. Knolrier: A quantitative appraisal of enzyme histochemical methods in brain tissue. J. Histochem. Cytochem. 11, 232-245 (1963).

${ }^{4}$ MtYake, K.: Zur Frage der Regeneration der Nervenfasern im zentralen Nervensystem. Arb. Neurol. Inst. Univ. Wien 14, 1-15 (1907).

${ }^{5}$ Ramon y CaJaL, S.: Degneration and regeneration of the nervous system. Raotl M. MaY (trans. and ed.). New York: Hafner Publ. Co. 1959.

${ }^{6}$ Schlote, W.: Morphologische und histochemische Untersuchungen an retrograden Axonveränderungen im Zentralnervensystem. Acta neuropath. (Berl.) 1, 135-158 (1961).

${ }^{7}$ Spatz, H.: Über die Vorgänge nach experimenteller Rückenmarksdurchtrennung. NrssLAlzHELvers Arbeiten über Großhirnrinde, Erg.-Bd., 49-364 (1921).

${ }^{8}$ WEBSTER, H. DE F.: Transient, focal accumulation of axonal mitochondria during the early stages of Wallerian degeneration. J. Cell Biol. 12, 361-383 (1962).

${ }^{9}$ WeIss, P.: Damming of axoplasm in constricted nerve; a sign of perpetual growth of nerve fibers. Anat. Rec. 88, 464 (1944).

10 - The concept of perpetual neuronal growth and proximo-distal substance convection, p. 220-242. In: Regional Neurochemistry. S. S. KETY and J. ELKes (ed.), p. 220-242. Pergamon Press 1961.

11 ZELENÁ, J., and L. Lu Biñska: Early changes of acetylcholinesterase activity near the lesion in crushed nerves. Physiol. bohemoslov. 11, $261-268$ (1962).

Dr. Reinhard L. Finiede M. D., Associate Professor of Pathology,

Mental Health Research Institute, Department of Psychiatry, The University of Miohigan, Ann Arbor/Michigan, United States 